LM), in 4 patients - joint effusion. Prevalence of PFJ, MF, MM, LM changes, osteophytes and Baker cysts didn't differ between groupsG. roups differed in PD signal expression in the synovia $(p=0,07)$. Functional association between VAS score and PD expression $(R=1,0, p<0,05)$ was revealed $\$$ moderate correlation between VAS score and joint effusion ( $R=0,47, p<0,05)$, PFJ $(R=0,58, p<0,05)$, osteophytes $(R=0,66, p<0,001)$ was observed.

Conclusion In the patients under study, degenerative and inflammatory findings were common in the symptomatic group, but were also identified in the asymptomatic patients. Clinical parameters were more strongly associated with active inflammation (as verified by US) rather than with degenerative changes.

Disclosure of Interests None declared

DOI: 10.1136/annrheumdis-2019-eular.8146

\section{AB1159 INTER-READER RELIABILITY AND COMPARISON OF FLUORESCENCE OPTICAL IMAGING ENHANCEMENT IN PATIENTS WITH EROSIVE HAND OSTEOARTHRITIS AND RHEUMATOID ARTHRITIS}

Øystein Maugesten ${ }^{1}$, Sarah Ohrndorf ${ }^{2}$, Daniel Glinatsi ${ }^{3}$, Mads AmmitzbøllDanielsen $^{3}$, Yogan Kisten ${ }^{4}$, Mikkel Ǿstergaard ${ }^{3}$, Lene Terslev ${ }^{3}$, Till Uhlig ${ }^{1}$, Tore K. Kvien ${ }^{1}$, Ida Kristin Haugen ${ }^{1}{ }^{1}$ Department of Rheumatology, Diakonhjemmet Hospital, Oslo, Norway; ${ }^{2}$ Charité Universitätsmedizin, Department of Rheumatology and Clinical Immunology, Berlin, Germany, ${ }^{3}$ Rigshospitalet, Glostrup, Center for Rheumatology and Spine Diseases, Copenhagen, Denmark; ${ }^{4}$ Karolinska University Hospital, Department of Medicine, Rheumatology Division, Stockholm, Sweden

Background: Fluorescence Optical Imaging (FOI) is an imaging technique demonstrating indocyanine (ICG)-enhanced microcirculation in wrist and finger joints, as a sign of inflammation. A reliable scoring method is essential in the assessment of these images.

Objectives: To assess inter-reader reliability of three FOI scoring methods from Berlin, Stockholm, and Copenhagen, and to compare the amount of enhancement in joint groups of both hands in patients with erosive hand osteoarthritis (OA) and rheumatoid arthritis (RA)

Methods: Patients with erosive hand $O A(n=13)$ and with RA $(n=13)$ underwent $\mathrm{FO}$ of both hands. Five readers blinded for clinical diagnoses scored all finger and wrist joints bilaterally on semi-quantitative 0-3 scales using three different $\mathrm{FOI}$ scoring methods. In the Berlin method, FOI enhancement was evaluated on three different images, defined as different phases based on the enhancement in the fingertips. A composite image (Prima Vista Mode, PVM) of the 240 first images was also assessed. The Copenhagen method assumed that inflamed tissues will demonstrate a more rapid $\mathrm{FOI}$ enhancement than the surrounding tissues, defining inflammation as sharply marginated enhancement over a joint area with clear delineation from surrounding tissues lasting $>3 \mathrm{sec}$. The Stockholm method was evaluated in PVM format of 240 and 120 images in 'temperature' palette setting, with additional scrolling through the image sequence to detect ambiguous signals. To evaluate inter-reader reliability, we calculated the intraclass correlation coefficients (ICC) of the sum scores on patient level and weighted kappa values and prevalence and bias adjusted kappa values for ordinal scales (Pabak-OS) on joint level. Finally, we compared the averaged sum scores in the different joint groups in patients with erosive hand OA vs. RA using the Mann-Whitney test.

Results: The ICC of the sum scores was very good for the Stockholm method (0.83), and for Berlin PVM (0.93) and Phase $2(0.83)$, while the Copenhagen method $(0.65)$ and Berlin phase $3(0.73)$ showed good reliability. Berlin phase 1 showed fair reliability $(0.30)$. On joint level we found moderate to good agreement with pabak-OS for all methods (table). Patients with erosive hand OA had significantly more enhancement in DIP joints across all methods, while PIP enhancement was more common in erosive hand $\mathrm{OA}$ for the Berlin PVM and Stockholm methods only. Enhancement in the $1^{\text {st }}$ CMC was not detected in any of the methods, and no consistent differences were observed for the wrist (data not shown).

Conclusion: We found moderate to very good inter-reader reliability on patient level for all methods except for Berlin phase 1 and moderate to good agreement on joint level for all methods. FOI showed different enhancement patterns between erosive hand $O A$ and RA, with more enhancement in the DIP joints in the OA patients across all methods, supporting its validity.

Disclosure of Interests: Øystein Maugesten: None declared, Sarah Ohrndorf: None declared, Daniel Glinatsi: None declared, Mads AmmitzbøllDanielsen: None declared, Yogan Kisten: None declared, Mikkel Ǿstergaard Grant/research support from: Abbvie, Celgene, Centocor, Merck, Novartis, Consultant for: Abbvie, BMS, Boehringer-Ingelheim, Celgene, Eli Lilly, Hospira, Janssen, Merck, Novartis, Novo, Orion, Pfizer, Regeneron, Roche, and UCB, Speakers bureau: Abbvie, BMS, Boehringer-Ingelheim, Celgene, Eli Lilly, Hospira, Janssen, Merck, Novartis, Novo, Orion, Pfizer,
Regeneron, Roche, and UCB, Lene Terslev Speakers bureau: Speakers fee from : Roche, Novartis, Pfizer, MSD, BMS, Celgene, Till Uhlig: None declared, Tore K. Kvien Grant/research support from: AbbVie, BMS, MSD, Pfizer, Roche and UCB., Consultant for: AbbVie, Biogen, BMS, Boehringer Ingelheim, Celgene, Celltrion, Eli Lilly, Hospira, Merck-Serono MSD, Novartis, Oktal, Orion Pharma, Pfizer, Roche, Sandoz, Sanofi, Mylan and UCB, Speakers bureau: AbbVie, Biogen, BMS, Boehringer Ingelheim, Celgene, Celltrion, Eli Lilly, Hospira, Merck-Serono, MSD, Novartis, Oktal, Orion Pharma, Pfizer, Roche, Sandoz, Sanofi and UCB, Ida Kristin Haugen Grant/research support from: ADVANCE research grant from Pfizer, Consultant for: Advisory board Abbvie

\begin{tabular}{|c|c|c|c|c|c|c|c|c|c|c|}
\hline \multicolumn{11}{|c|}{$\begin{array}{l}\text { Weighted kappa and prevalence and bias adjusted kappa for ordinal scales (Pabak-OS) for different } \\
\text { joint groups }\end{array}$} \\
\hline & \multicolumn{2}{|c|}{ All joints } & \multicolumn{2}{|c|}{ DIP 2 - 4} & \multicolumn{2}{|c|}{ PIP 2 - 4} & \multicolumn{2}{|c|}{ MCP 1 - 5} & \multicolumn{2}{|c|}{ Wrist } \\
\hline & $\begin{array}{c}\text { W. } \\
\text { kappa }\end{array}$ & $\begin{array}{c}\text { Pabak } \\
\text { OS }\end{array}$ & $\begin{array}{c}\text { W. } \\
\text { kappa }\end{array}$ & $\begin{array}{c}\text { Pabak } \\
\text { OS }\end{array}$ & $\begin{array}{c}\text { W. } \\
\text { kappa }\end{array}$ & $\begin{array}{c}\text { Pabak } \\
\text { OS }\end{array}$ & $\begin{array}{c}\text { W. } \\
\text { kappa }\end{array}$ & $\begin{array}{c}\text { Pabak } \\
\text { OS }\end{array}$ & $\begin{array}{c}\text { W. } \\
\text { kappa }\end{array}$ & $\begin{array}{c}\text { Pabak } \\
\text { OS }\end{array}$ \\
\hline Berlin PVM & 0.51 & 0.78 & 0.47 & 0.74 & 0.58 & 0.72 & 0.53 & 0.84 & 0.45 & 0.79 \\
\hline Berlin P1 & 0.44 & 0.69 & 0.26 & 0.69 & 0.30 & 0.56 & 0.60 & 0.83 & 0.61 & 0.81 \\
\hline Berlin P2 & 0.44 & 0.50 & 0.43 & 0.56 & 0.51 & 0.58 & 0.37 & 0.38 & 0.45 & 0.51 \\
\hline Berlin P3 & 0.37 & 0.62 & 0.36 & 0.77 & 0.40 & 0.57 & 0.30 & 0.56 & 0.40 & 0.62 \\
\hline Stockholm & 0.40 & 0.63 & 0.41 & 0.61 & 0.39 & 0.47 & 0.45 & 0.74 & 0.34 & 0.71 \\
\hline Copenhagen & 0.39 & 0.56 & 0.39 & 0.65 & 0.30 & 0.35 & 0.52 & 0.70 & 0.36 & 0.48 \\
\hline
\end{tabular}

Table 1

DOI: 10.1136/annrheumdis-2019-eular.1912

\section{AB1160 INVOLVEMENT OF ANKLE JOINTS AND TENDONS IN SYSTEMIC LUPUS ERYTHEMATOSUS: AN ULTRASOUND STUDY}

Ljiljana Smiljanic Tomicevic, Darija Cubelic, Goran Sukara, Branimir Anic, Miroslav Mayer. University Hospital Centre Zagreb, University of Zagreb, School of Medicine, Department of Internal Medicine, Division of Clinical Immunology and Rheumatology, Zagreb, Croatia

Background: Systemic lupus erythematosus (SLE) is a chronic autoimmune disease with heterogeneous clinical manifestations. The musculoskeletal involvement is among commonest and earliest symptoms occurring in $95 \%$ of patients. The clinical examination of the ankle joints may underestimate the type and distribution of pathological changes. Musculoskeletal ultrasound (US) is a useful diagnostic tool for evaluation of joints and tendons in the majority of inflammatory rheumatic diseases.

Objectives: The aim of this study is to assess the ankle joints and tendons involvement in SLE patients using US and to correlate the findings with the physical examination, laboratory tests and disease activity scores. Methods: Forty consecutive SLE patients were enrolled in the study and underwent clinical evaluation, laboratory tests and bilateral high-resolution US on the same day. Grey-scale and power Doppler (PD) US of the talocrural (TC), subtalar joints (ST), ankle tendons, second and third MCP joints, second and third PIP joints, wrists and second and third MTP joints were performed.

Results: A total of 720 joints and 800 tendons were examined. US detected inflammatory joint abnormalities were present in $35 / 40$ (87.5\%) patients while tenosynovitis was present in $7 / 40(17,5 \%)$ patients. The most frequently affected were MTP joints $(67,5 \%)$ followed by $\operatorname{MCP}(42,5 \%)$ and TC joints $(40 \%)$, wrists $(27,5 \%)$ and PIP joints $(7,5 \%)$. The most prevalent pathological US finding was joint effusion.Synovial hypertrophy and positive PD signal were less frequently observed. Effusion in TC joints was present in $40 \%$, synovial hypertrophy in $20 \%$ and positive PD in $2,5 \%$ of the patients. Only two patients had bony erosions detected.Six out of forty patients (15\%) reported pain or swelling in ankle joints and two(33\%) of them didn't have any US abnormalities.As many as $47 \%$ of patients without inflammatory joint symptoms had pathological US findings in ankle joints. The most commonly affected tendon was tibialis anterior (7,5\% of patients), followed by extensor halluces longus tendon ( $5 \%$ of patients).

Conclusion: Results of this study show a high prevalence of US verified inflammatory joint changes in SLE patients, while tendon changes were extremely rare. Foot joints were most commonly affected, followed by wrists and ankle joints. It is important to stress that a great number of asymptomatic patients had pathological US findings in ankle joints. From this and previous studies it is clear that US should be used more in the periodical assessment of the musculoskeletal system in patients with SLE. 